Pathophysiology

of Haemostasis and Thrombosis

\title{
Glanzmann thrombasthenia: a model disease which paved the way to powerful therapeutic agents
}

\author{
Uri Seligsohn
}

Institute of Thrombosis and Hemostasis, the Chaim Sheba Medical Center, Tel Hashomer and Sackler Faculty of Medicine, Tel Aviv University, Israel

\section{Key Words}

Glanzmann thrombasthenia, glycoproteins IIb and IIla, antiplatelet drugs

\begin{abstract}
Glanzmann thrombasthenia (GT) is an autosomal recessive bleeding disorder characterized by deficient or dysfunctional glycoprotein (GP) Ilb/lla compexes. The hallmark of the disease is impaired platelet aggregation stemming from defective fibrinogen binding to GPIlb/llla. Based on deciphering the abnormality in GT a monoclonal antibody, peptides and peptidominetic agents, all interfering with fibrinogen binding to GPIIb/III complex, have been developed and successfully used to create a transient thrombasthenia - like state in patients with imminent arterial thrombosis. Currently, the main benefit afforded by these agents has been observed in patients undergoing percutaneous coronary interventions who are at high risk of thrombosis but more indications for their use are evolving.
\end{abstract}

Copyright (c) 2002 S. Karger AG. Basel

Glanzmann thrombasthenia (GT) is an autosomal recessive disorder which manifests as a life long moderate to severe bleeding tendency. Bleeding is mainly mucocutaneous and the first episode, facial purpura, is frequently encountered in affected newborns following labour. Unlike in the hemophilias, hemarthrosis, hematuria and intracerebral hemorrhage occur very rarely in patients with GT. Affected patients exhibit a prolonged bleeding time, absent clot retraction and failure of platelets to aggregate in response to ADP, collagen, thrombin and epinephrine, but ristocetin - induced aggregation remains intact. The first clue for understanding the molecular basis of the disease was the discovery of glycoprotein (GP) IIb and IIIa deficiency in platelets of affected patients in the 70s [1].

Several clusters of patients with GT have been reported in France, India, and among Iraqi Jews in Israel and among Arabs in Israel and Jordan. Studies of these and other patients from different parts of the world by use of monoclonal antibodies against GPIIb or GPIIIa revealed that the disease is quite heterogeneous. Use of these antibodies was nevertheless instrumental for the development of assays for carrier detection and prenatal diagnosis. For example, use of ${ }^{125} \mathrm{I}$-labelled 10E5 monoclonal antibody which recognizes the GPIIb/IIIa complex enabled distinction among obligatory carriers, patients and healthy controls with a high specificity and sensitivity [2]. This method also enabled the performance of prenatal diagnosis by analysis of platelets obtained during fetal blood sampling [3].

Following the cloning and sequencing of the cDNAs for GPIIb and GPIIIa in the 80s the molecular genetic basis of GT became possible by making use of the small amounts of RNA present in platelets, reverse transcribing it and amplifying segments of the cDNA and sequencing. The first mutations which

\section{KARGER \\ (c) 2002 S. Karger AG. Base \\ $1424-8832 / 02 / 0326-0216 \$ 18.50 / 0$}

U. Seligsohn, M.D

Institute of Thrombosis and Hemostasis Sheba Medical Center Tel-Hashomer 52621 - Israel - Tel: 972-3-5302104 - Fax: 972-3-5351568

E-Mail: seligson@sheba.health.gov.il

Postal address: U. Seligsohn, M.D., Institute of Thrombosis and

Hemostasis, Sheba Medical Center, Tel-Hashomer

52621, Israel 
cause GT were discovered in 1991, among which were an 11 bp deletion of the GPIIIa gene in exon 12 in Iraqi Jews leading to a stop, and a 13 bp deletion of the GPIIb gene in the splice site and part of exon 4 in Arabs leading to a deletion of 6 amino acids (4). Later studies revealed that in a few other Iraqi Jewish families there was another mutation (a $11.2 \mathrm{~kb}$ deletion). For both the $11 \mathrm{bp}$ and $11.2 \mathrm{~kb}$ mutations founder effects were discernable (5). Currently, more than 100 mutations in either GPIIb gene or GPIIIa gene have been reported with many of them introduced into a data base prepared by Dr. Debra French (http://med.mssm.edu/glanzmann.db). Characterization of these mutations has shed light on understanding the essential sites of interaction between GPIIb and GPIIIa during intracellular complex formation, transport, and membrane expression. Moreover, clues for understanding the interaction between the GPIIb/IIIa complex and its main ligand fibrinogen have been identified through studies of the "unsuccessful experiments of nature" that have given rise to GT.

For many years it has been hypothesized that patients with severe inherited impairment of hemostasis are protected against cardiovascular disease. Indeed, protection against myocardial infarction was demonstrated in patients with severe hemophilia A and B. This protection seemed to be conferred mainly by suppressing the thrombotic occlusion of coronary arteries and not by inhibiting the development of arteriosclerosis [6]. We have recently demonstrated that patients with GT are not protected against arteriosclerosis similarly to hemophilia A and hemophilia B patients [7]. However, it will remain to be seen whether or not patients with GT are naturally protected against thrombotic events.

Following the recognition that platelet adhesion and aggregation play a major role in causing occlusive arterial thrombosis it appeared logical to target platelet aggregation for treatment and prevention of arterial thrombosis. Aspirin blocking throboxane A2 synthesis, and clopidogrel blocking ADPmediated platelet aggregation are good antithrombotic agents but leave thrombin-induced platelet aggregation unaffected. Since the final common pathway of platelet aggregation is the expression of functionally active GPIIb/IIIa complex, and since ligand binding sites have been identified, the GPIIb/IIIa has become a target for development of new antithrombotic agents. A patient with GT who developed a unique powerful antibody against GPIIb/IIIa following multiple transfusions appeared to be a potential source of a therapeutic agent [8]. However, attempts in the late 80 s to produce a human-human hybridoma from this patient for production of the antibody were unsuccessful (Coller BS and Seligsohn U, unpublished). Instead, a powerful murine monoclonal antibody (7E3) produced by Dr. Barry Coller was "humanized" by linking part of its FAB fragment to human FAB. Following successful animal experiments the antibody (abciximab) was introduced into clinical practice showing significant reduction in the combined endpoint of acute myocardial infarction, need for emergency coronary artery bypass grafting and mortality in patients undergoing percutaneous coronary intervention (PCI). Other agents targeting the GPIIb/IIIa complex are naturally occurring (derived from a snake venom), synthetic RGD (Arg-Gly-Asp) - containing peptides, and peptidomimetic agents. All these agents have been and are being under intensive investigation in numerous studies with promissing results. While success has been achieved to a greater or lesser degree in patients undergoing PCI by use of these agents, questions have arisen, such as whether these agents will exert an additional benefit when using new stents which prevent restenosis or low molecular weight heparin rather than regular heparin. It will also remain to be established whether the anti GPIIb/IIIa agents will exhibit a benefit in patients with carotid, cerebral or peripheral artery percutaneous interventions.

\section{References}

1. Nurden AT, Caen JP: An abnormal platelet glycoprotein pattern in three cases of Glanzmann's thrombasthenia. Br J Haematol 1974;28:253-260.

2. Coller BS, Seligsohn U, Zivelin A, Zwang E, Lusky A, Modan M: Immunologic and biochemical characterization of homozygous and heterozygous Glanzmann thrombasthenia in the Iraqi-Jewish and Arab populations of Israel: comparison of techniques for carrier detection. Br J Haematol 1986;62:723-733.

3. Seligsohn U, Mibashan RS, Rodeck $\mathrm{CH}$, Nicolaides KH, Millar DS, Coller BS: Prenatal diagnosis of Glanzmann's thrombasthenia. Lancet $1985 ; 2: 1419$.
4. Newman PJ, Seligsohn U, Lyman S, Coller BS: The molecular genetic basis of Glanzmann thrombasthenia in the Iraqi-Jewish and Arab populations in Israel. Proc Natl Acad Sci USA 1991;88:3160-3164.

5. Rosenberg N, Yatuv R, Orion Y, Zivelin A, Dardik R, Peretz H, Seligsohn U: Glanzmann thrombasthenia caused by an $11.2-\mathrm{kb}$ deletion in the glycoprotein IIIa (beta3) is a second mutation in Iraqi Jews that stemmed from a distinct founder. Blood 1997;89:3654-3662.

6. Sramek A, Reiber JH, Gerrits WB, Rosendaal FR:Decreased coagulability has no clinically relevant effect on atherogenesis: observations in individuals with a hereditary bleeding ten- dency. Circulation 2001;104:762-767.

7. Shpilberg O, Rabi I, Schiler K, Walden R, Harats D, Tyrrell KS, Coller B, Seligsohn U: Patients with Glanzmann thrombasthenia lacking platelet glycoprotein alpha(IIb)beta(3) (GPIIb/IIIa) and alpha(v)beta(3) receptors are not protected from atherosclerosis. Circulation 2002;105:1044-1048.

8. Coller BS, Peerschke EI, Seligsohn U, Scudder LE, Nurden AT, Rosa JP:Studies on the binding of an alloimmune and two murine monoclonal antibodies to the platelet glycoprotein IIb-IIIa complex receptor. J Lab Clin Med 1986;107:384-392. 